\title{
Assessment of the marketing and innovative potential of synbiotic products with herbal biocorrector
}

\author{
Natalya Rodionova*, Alexander Rodionov, Irina Shchetilina, Marina Manukowskaya, Mariya Rusanova,and Tatyana \\ Razinkova
}

Service and restaurant business department, Voronezh State University of Engineering Technologies, Voronezh, Russian Federation

\begin{abstract}
The article presents the results of studies of the relationship of potential consumers to new synbiotic products with predictably formed functional, prebiotic properties and biological activity. The assessment of the prospects of including the developed bioactive synbiotic products in the recipes of dishes of public catering enterprises and giving them functional properties is given. The main sociodemographic characteristics and preferences of consumers in relation to synbiotic products with compositions of bioactive plant components have been identified. The trends of needs change, their duality, dilemmas, reality and problems of the main drivers relevant to the modern consumer, price expectations, preferred options for introducing bioactive synbiotic products into the diet are revealed. The study allows us to draw a conclusion about the need to take into account when developing new technologies and reflect in the information and advertising materials the identified consumer expectations regarding the taste, usefulness, safety, convenience and authenticity of new products, including synbiotic with plant-based biological active components, and their introduction into food recipes is a promising direction for the development of enterprises of the HoReCa segment. The results of the study, carried out with a focus on enterprises in the public catering sector, seem relevant, since the use of synbiotic products with herbal biological components is an expansion of opportunities for food and bio-technologies, public catering organizations with justified socio-economic effect.
\end{abstract}

\section{Introduction}

In a service economy, an important step in creating a new functional product and launching it on the market is to predict its marketing potential and relevance. It is necessary to assess the potential demand and identify the portrait of the target group of consumers, which is the result of marketing research [1].

\section{Experimental}

Marketing research was carried out by the survey method, which makes it possible to obtain information about the current state of the research object, as well as about trends and intentions in the future.

In the course of marketing research, the following tasks were formulated and implemented: specification of the relationship of potential consumers to new synbiotic products for a healthy diet containing vegetable biologically active compositions; assessment of the prospects for the implementation of the developed products in the HoReCa segment, identification of the main socio-demographic characteristics and preferences of the target group in relation to synbiotic products with compositions of bioactive plant components (CBRC); building a pricing model for synbiotic products with $\mathrm{CBRC}$ and dishes using them [2,3].

To implement the formulated tasks, the general population of residents of Voronezh and the region was determined. As criteria for the formation of this *Corresponding author: rodionovast@mail.ru population, social status, age and sex characteristics, marital and material status were determined.

\section{Results and discussion}

As a result of the study of the main values of consumers when making a decision on the purchase and processing of the results, the following data were obtained (Figure $1)$.

The safety of the product is absolutely important (100\% of positive answers), from 80 to $100 \%$ of respondents noted the importance of the taste of the product, its usefulness, cost, ease of consumption, authenticity.

At the same time, $68 \%$ of respondents said that they lead a healthy lifestyle (Figure 2) [4].

Each of the factors identified by the respondents characterizes the actual need of the modern consumer, and the list of needs and their characteristics tend to change at this stage of the development of the service economy (Table 1).

Analysis of the results of the interview with the respondents revealed the essence of the needs and their transformation in the paradigm of the modern consumer attitude to food products.

When concretizing the useful properties of the new synbiotic products, the respondents were listed the positive effects of their use (Figure 3). Among the most anticipated effects were identified: restoration of energy balance (70 respondents), prophylaxis of gastrointestinal 
diseases (63 respondents), anti-aging effect (48 respondents), prevention of cardiovascular diseases (14 respondents), prevention and treatment of skin diseases (12 respondents) [5, 6].

As a result of the survey, a tendency toward the duality of product characteristics, due to existing realities, was revealed - wholesome products may not always be convenient in consumption or tasty enough or guaranteed to be safe. For example, with a generally positive attitude to farm milk products, some respondents expressed concerns about its safety. The main options for the needs dilemmas and emerging problems are described in Table 2.

Table 1. Characteristics of Needs and their Potential Changes

\begin{tabular}{|c|c|c|}
\hline Need & Characteristic & Development trends \\
\hline Security & $\begin{array}{l}\text { Prime value, } \\
\text { increased } \\
\text { demands }\end{array}$ & $\begin{array}{c}\text { Compliance with } \\
\text { standards } \rightarrow \text { transparency } \\
\text { of composition, sources, } \\
\text { technologies }\end{array}$ \\
\hline Benefit & $\begin{array}{r}\text { The pursuit } \\
\text { of healthy food }\end{array}$ & $\begin{array}{l}\text { Health trend } \rightarrow \\
\text { healthy habits }\end{array}$ \\
\hline Convenience & $\begin{array}{l}\text { The ability to } \\
\text { eat better every } \\
\text { day }\end{array}$ & $\begin{array}{r}\text { Compromise } \rightarrow \text { daily } \\
\text { consumption opportunity }\end{array}$ \\
\hline Taste & $\begin{array}{l}\text { Movement to } \\
\text { natural } \\
\text { sensations }\end{array}$ & $\begin{array}{l}\text { Artificial «Notes» } \rightarrow \\
\text { natural tastes }\end{array}$ \\
\hline Authenticity & $\begin{array}{c}\text { Meeting } \\
\text { unique needs }\end{array}$ & $\begin{array}{l}\text { One universal format } \\
\text { for everyone -> } \\
\text { authenticity }\end{array}$ \\
\hline
\end{tabular}

Solving the dilemmas formulated by the respondents will provide a competitive advantage for new products and become a source of active business development in the segment of healthy and healthy products. Today, dairy, and in particular, probiotic products maintain the image of healthy ones [7 - 9].

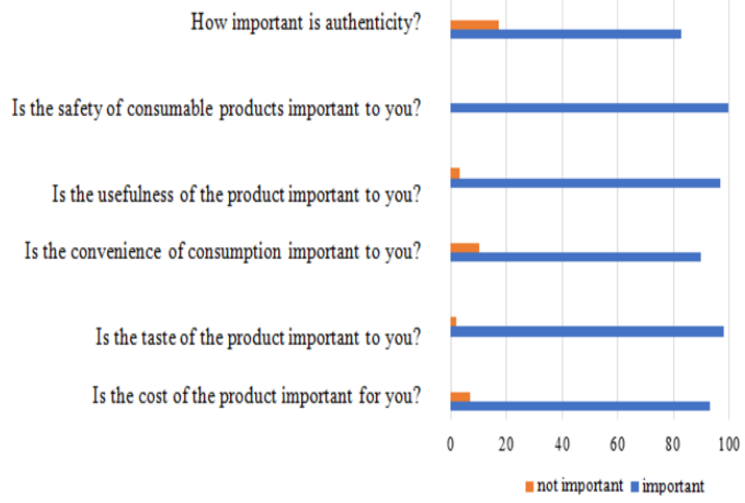

Fig. 1. Distribution of answers to the questions "What is important for you when buying a new synbiotic product?»

According to the results of the study, recognition of probiotic, prebiotic and synbiotic products is currently quite high. $90 \%$ of the participants have heard about this group of products, only $7 \%$ are not familiar with these products (Figure 4).

In order to identify potential preferences and demand for new synbiotic products and culinary products with their use, the question was asked - would they like these products to be on the menu of HoReCa enterprises, the dishes had a probiotic effect and were more useful as a result of introducing formulations of natural plant biologically active ingredients. As a result, $40 \%$ of respondents said that they would like to see more wholesome dishes in the menu of enterprises in the HoReCa sector due to the introduction of probiotic microorganisms and biologically active plant components (Figure 5) [10,11].

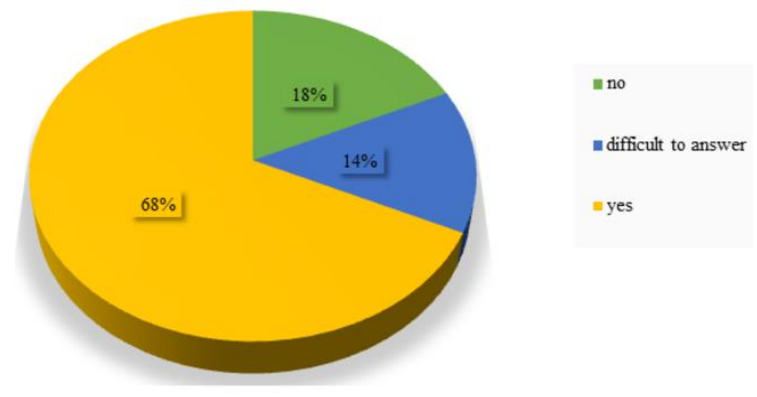

Fig. 2. Distribution of answers to the question: «Do you relate to people who adhere to a healthy lifestyle?»

An important stage of marketing research was the question of determining the type of catering establishment in which respondents would be ready to buy dishes with probiotics and bioactive ingredients (Figure 6). In accordance with the data obtained, the answers were distributed as follows: a democratic restaurant-cafe (60\%), fast food (23\%), a dining room $(13 \%)$, a classic restaurant $(4 \%)$.

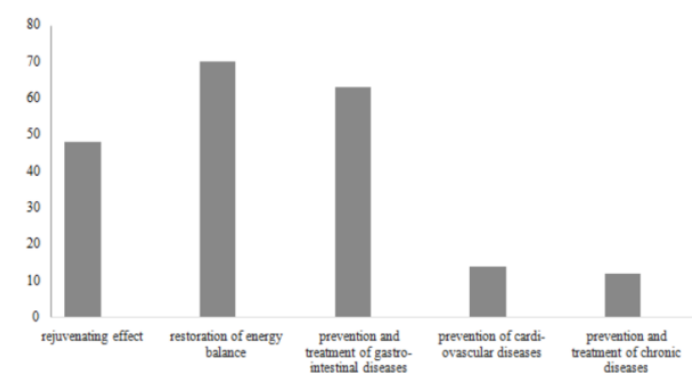

Fig. 3. Analysis of respondents' opinions on useful properties, innovative products

An important factor in promoting a new product on the food market is determining the possible type of dish (Figure 7).

The largest number of respondents (41) noted the preference for introducing synbiotic products with biologically active herbal supplements into the main dishes, $23 \%$ preferred functional desserts and drinks, 20 $\%$ preferred first courses, and only $2 \%$ preferred sauces. However, it should be noted that sauces, as a rule, are part of main dishes or desserts (sweet sauces), therefore sauces, dressings, dressings with probiotics and bioactive ingredients can give functional properties to both the second dish and dessert.

To determine the solvency level of respondents, the question was asked about the size of the average check, when visiting a catering facility (Figure 8), it was found that the average check is more than 1000 rubles acceptable for $29 \%$ of survey participants, 500-1000 rubles $-34 \%$ of respondents pay, up to 500 rubles -37 $\%$. 
To solve the question of the possibility of determining the premium level of prices for synbiotic products and dishes of increased functionality with their application, the question was asked in the questionnaire: «Are you ready to pay a higher price for a dish or product?». It was found that $45 \%$ of respondents agreed to raise prices in the range of $20-50 \%, 29 \%$ found it difficult to answer, and $26 \%$ did not agree with the appointment of a premium price (Figure 9).

When detailing the properties and updating the characteristics of new products for which potential consumers were ready to pay a premium price, the following results were obtained: $90 \%$ - for high quality and safety, $84 \%$ - for high consumer properties, $80 \%$ for natural ingredients and authenticity, $77 \%$ for organic, organic foods in the dish (Figure 10).

Thus, the newly developed products must satisfy the requirements of the premium segment in terms of their characteristics, but at the same time they must be reasonably democratic in price.

When deciding on the release of a new product, it is necessary to evaluate the potential market capacity. As a period for which an assessment of the potential market capacity was carried out, a month was chosen.

Table 2. Dualism of Needs: Dilemmas and Arising Challenges

\begin{tabular}{|l|l|l|}
\hline \multicolumn{1}{|c|}{$\begin{array}{c}\text { Desirability of driver- } \\
\text { dilemma interactions }\end{array}$} & \multicolumn{1}{|c|}{ Reality } & \multicolumn{1}{|c|}{ Problems } \\
\hline Taste + Benefit & $\begin{array}{l}\text { Healthy nutrition is not always tasty. Highly processed foods } \\
\text { rich in fats, calories, and flavor enhancers are more attractive. }\end{array}$ & $\begin{array}{l}\text { How to make healthy foods more } \\
\text { tasty? }\end{array}$ \\
\hline Convenience + Benefit & $\begin{array}{l}\text { Healthy eating takes a lot of time and effort. Fast food is fast, } \\
\text { but harmful. }\end{array}$ & $\begin{array}{l}\text { How to make healthy products } \\
\text { convenient? }\end{array}$ \\
\hline Benefit + Security & $\begin{array}{l}\text { Healthy foods are rich in nutrients and do not contain } \\
\text { preservatives, they are difficult to store, they may not be safe } \\
\text { during storage. }\end{array}$ & $\begin{array}{l}\text { How to make preservative-free } \\
\text { foods safe? }\end{array}$ \\
\hline Taste + Security & $\begin{array}{l}\text { Taste is the main thing in the evaluation of the product. The } \\
\text { most delicious products in small-scale production, but they are } \\
\text { often unsafe. }\end{array}$ & $\begin{array}{l}\text { How to make small-scale } \\
\text { production safe? }\end{array}$ \\
\hline Authenticity + Security & $\begin{array}{l}\text { Authentic home-made foods are tasty but can be unsafe. } \\
\text { Increased confidence in industrial products. }\end{array}$ & $\begin{array}{l}\text { How to make authentic products } \\
\text { safer? }\end{array}$ \\
\hline
\end{tabular}

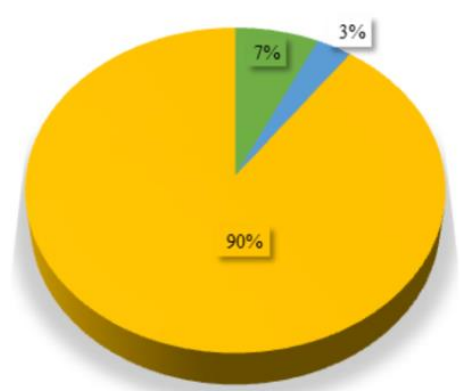

$=$ no

= difficult to answer

"yes

Fig. 4. Awareness of respondents about the availability of probiotic, prebiotic and synbiotic products on the market
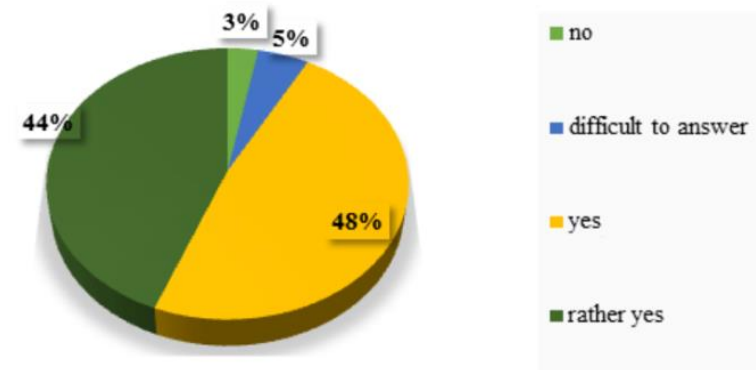

Fig. 5. The relevance of the introduction of dishes with probiotics and a composition of bioactive plant components in the menu of catering establishments

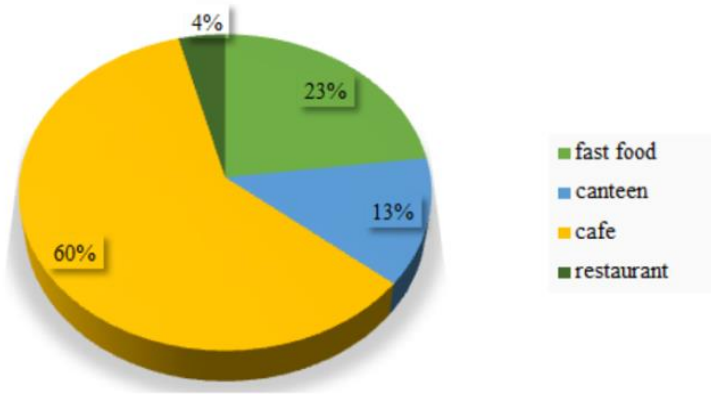

Fig. 6. Preference of respondents in the segment of the restaurant market enterprises

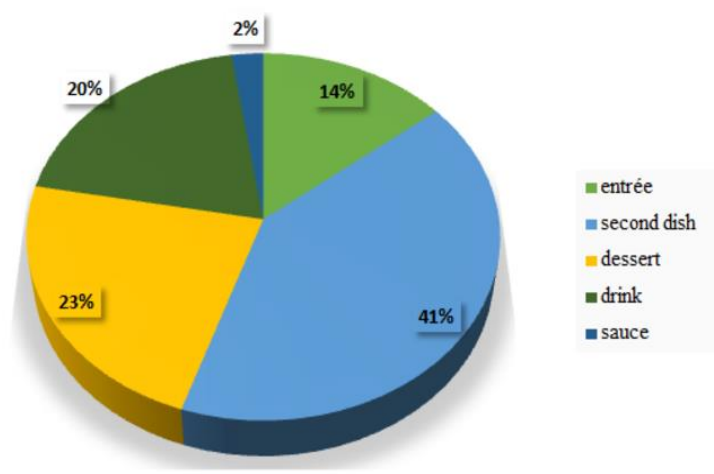

Fig. 7. Consumer preference for a group of dishes for the introduction of a synbiotic product 


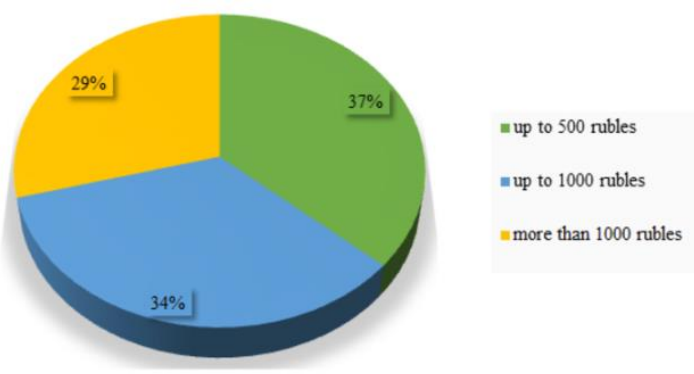

Fig. 8. Determining the preferred average check amount per respondent

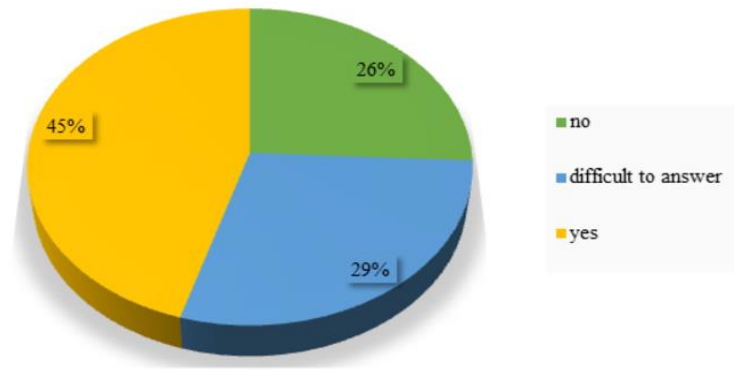

Fig. 9. Opinion of the respondents about the increase in the price of the studied group of goods

Synthetic dairy products with enhanced CBRC functionality are recommended for enterprises that organize catering for schoolchildren, athletes, students, sanatorium-and-prophylactic and medical institutions, for workers of industrial enterprises with adverse working conditions, for preventive measures and correction of biocenosis disorders, increase immunity, cancer prevention, alleviate the condition of patients undergoing antibiotic, radiation, cytostatic and chemotherapy.

Products contain highly active consortia of lactobacilli and bifidobacteria:

«Immunolact-nova» - contains in active form a probiotic culture of L. Casei subsp. Rhamnosus;

«Bifilux-nova» - contains in its active form bifidobacteria Bifidobacterium bifidum, Bifidobacterium longum, Bifidobacterium adolescentis, Bifidobacterium bifidum Y-4;

«Lactinal nova» - contains in active form pro-biotic cultures of Lactobacillus acidophilus, Lactobacillus plantarum, Lactobacillus fermentum, Lactobacillus casei subsp. Rhamnosus;

«BioMatrix-nova» - contains in active form probiotic cultures of L. Casei subsp. Rhamnosus, L. acidophilus, L. plantarum, L. fermentum, Bifidobacterium bifi-dum, Bifidobacterium longum, Bifidobacterium adolescentis.

Probiotic action of consortia used as direct starter cultures (according to the producer of Bioproduct LLC).

As prebiotic food additives, which form additional functional properties of pro-biotic products containing consortia of enumerated probiotic microorganisms, dietary supplements «Vitazar», «Flavocene», «Flarabin», «Seleksen», «Inulin», «Iodcasein» and their compositions, providing additional immunomodulating, antioxidant, prebiotic, vitaminizing properties, can be added to the composition of the proposed products.
The concentration of probiotic microorganisms is not less than $10^{8}-10^{9} \mathrm{CFU} / \mathrm{ml}$, which provides a high concentration of metabolites formed as a result of acid hydrolysis of probiotic bacteria in the stomach $(99 \%$ of their initial content) and maintaining a high proportion of active forms when leaving stomach $\left(10^{7} \mathrm{CFU} / \mathrm{ml}\right)$.

The product is produced from specially selected farm milk, milk is not subjected to harsh thermal and mechanical influences, it is pasteurized and fermented at rest by a thermostatic method.

The most important stage of the planned work at the enterprises is the determination of the cost of production and sale of a unit of production of each type. This calculation serves as the basis for establishing the design wholesale price of products and the effectiveness of their production.

The unit cost of production was calculated using the well-known calculation method - assigning all expenses to the production and sale of products $(1 \mathrm{~kg})$ for all types of production program (TABLE $3,4,5$ ).

The source data for calculating the cost of marketable products are the plan for the production and sale of products in physical terms and the cost of production.

The risk of lack of sales is low, but in order to reduce it, it is advisable to conclude agreements on the supply of products for school canteens, canteens of various enterprises, educational institutions of vocational education at various levels, medical institutions already at the stage of preparation for production.

It is also necessary to ensure strict quality control of finished products, which can also help reduce the risk of lack of sales.

A business plan has been developed for the production of synbiotic sour-milk products with the CBRC, in the conditions of the Scientific-Industrial Complex of VSUET. Selected industrial equipment of the required productivity. The number of teaching staff and payroll, the consumption of raw materials, auxiliary materials, energy consumption and depreciation of fixed assets are calculated.

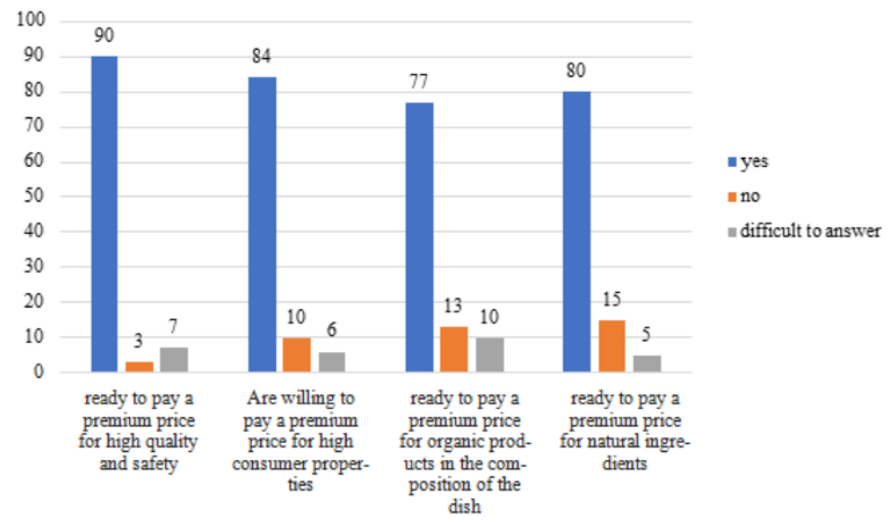

Fig. 10. The willingness of respondents to pay a premium price for current characteristics

Key performance indicators presented in TABLE 6. Based on the calculated indicators, the planned revenue from the sale of products $(179040.76$ thousand rubles per year) and the planned profit $(88,520.38$ thousand rubles 
per year) are determined. The main financial and economic indicators prove the economic feasibility of introducing the developed technologies into production activities: with a production volume of about 988 tons per year, the economic effect from the implementation of the proposed technological solutions will amount to 90 thousand rubles. per 1 ton of products. The payback period for capital investments will be 10 months.

\section{Conclusion}

The study allows us to conclude that the production of synbiotic products with a composition of plant biological active components in the HoReCa segment is promising and cost-effective. Launching on the market of synbiotic products enriched with herbal compositions is of great social importance for maintaining the health and preventing diseases of the population in the face of environmental degradation, the presence of psycho- emotional imbalances, and the accelerating pace of life of urban residents [12 - 14].

The results of the study, carried out with a focus on enterprises in the food service sector, seem relevant, since it is the developed network of enterprises in the HoReCa sector that can provide the maximum effect from the positive effect of pro-biotics and plant bioadditives on the human body, including socio-economic. Based on the calculated indicators, the planned revenue from the sale of products $(179040.76$ thousand rubles per year) and the planned profit $(88,520.38$ thousand rubles per year) are determined. The main financial and economic indicators prove the economic feasibility of introducing the developed technologies into production activities: with a production volume of about 988 tons per year, the economic effect from the implementation of the proposed technological solutions will be 90 thousand rubles. per 1 ton of manufactured products. The payback period for capital investments will be 10 months.

Table 3. Calculation of product costs

\begin{tabular}{|c|c|c|c|c|}
\hline \multirow{2}{*}{ Costs per $1000 \mathrm{~kg}$, rubles, by type } & \multicolumn{4}{|c|}{ The synbiotic product «Biomatrix» with herbal compositions } \\
\hline & KBRK Se & KBRK I & KBRK A & KBRK F \\
\hline Supporting materials & \multicolumn{4}{|c|}{21800,0} \\
\hline $\begin{array}{l}\text { Fuel and energy for technological } \\
\text { purposes }\end{array}$ & \multicolumn{4}{|c|}{1829,0} \\
\hline Basic and additional wages & \multicolumn{4}{|c|}{7743,19} \\
\hline Payroll deductions & \multicolumn{4}{|c|}{2477,7} \\
\hline Maintenance and equipment costs & \multicolumn{4}{|c|}{2477,7} \\
\hline
\end{tabular}

Table 4. Calculation of product costs

\begin{tabular}{|c|c|c|}
\hline \multirow[b]{2}{*}{$\begin{array}{l}\text { Biomatrix synbiotic product with } \\
\text { vegetable compositions }\end{array}$} & \multicolumn{2}{|c|}{ Costs per $1000 \mathrm{~kg}, \mathrm{p}$, by type } \\
\hline & $\begin{array}{c}\text { Raw materials and basic materials } \\
\text { minus waste }\end{array}$ & Production cost \\
\hline KBRK Se & 61,50 & 94131 \\
\hline KBRK I & 38,00 & 73108 \\
\hline KBRK A & 63,00 & 98108 \\
\hline KBRK F & 64,00 & 99108 \\
\hline
\end{tabular}

Table 5. Calculation of the value of goods for the annual volume of production 247 Ton

\begin{tabular}{|c|c|c|c|}
\hline $\begin{array}{c}\text { The synbiotic } \\
\text { product «Biomat- } \\
\text { Ricks» with herbal } \\
\text { compositions }\end{array}$ & $\begin{array}{c}\text { Cost of marketable } \\
\text { products, rubles / ton }\end{array}$ & $\begin{array}{c}\text { Unit price, thousand rubles for 1 } \\
\text { ton }\end{array}$ & $\begin{array}{c}\text { The cost of marketable } \\
\text { products, thousand } \\
\text { rubles }\end{array}$ \\
\hline KBRK Se & 94131 & 188,262 & 46500,71 \\
\hline KBRK I & 73108 & 146,216 & 35115,35 \\
\hline KBRK A & 98108 & 196,216 & 48465,35 \\
\hline KBRK F & 99108 & 198,216 & 48959,35 \\
\hline
\end{tabular}

Table 6. Main technical and economic indicators of production of synbiotic products with vegetable compositions

\begin{tabular}{|c|c|}
\hline Indicators & The values of economic indicators \\
\hline Revenue, thousand rubles & 179040,76 \\
\hline Cost of sales, thousand rubles & 89520,38 \\
\hline Profit from the sale of products, thousand rubles & 89520,38 \\
\hline The number of PPP, people & 9 \\
\hline Labor payment fund, thousand rubles & 1912,56 \\
\hline the average monthly salary of the 1st employee of the PPP, & 17,700 \\
\hline Labor productivity, thousand rubles & 0,50 \\
\hline Costs for 1 ruble of marketable products, cop. & 3752,00 \\
\hline Capital investments, thousand rubles & 3978,50 \\
\hline Current assets, thousand rubles & 53,280 \\
\hline Product Profitability, $\%$ & 10 \\
\hline
\end{tabular}




\section{References}

1. V. M. Kiselev, Exclusive marketing, 3, 32-42 (2013)

2. S. M. Zakharenko and A. N. Suvorov, Consiliummedicum, 8(11), 47-51, (2009)

3. I. V. Dharma, I. A. Landowski, K. E. Gavrilov, I. Yu Chicherin, and I. Pogorelsky, "Probiotics: development. Practical medicine," 3(58), 180-188 (2012)

4. S. Bengmark [eds. P.J. Heidt, V. Rusch, D. van der Waaij, and T. Midtvedt, "Synbiotic treatment in Clinical Praxis,” in: Host MicrolloraCrosstalk, Old Herborn University Seminar, 16. pp.69-82 (2003)

5. M. D. Collins and G. R. Gibson Am.J.Clin.Nutr., 69(5), 1052-1057 (1999)

6. A. L. Meyer, M. Micksche, I. Herbacek et al., Ann. Nutr. Metab, 50(3), 282-289 (2006)

7. S. G. Sazawal, U. Hiremath, P. Dhingra, P. Malik, and S. Deb, Lancet Infect Dis., 6, 374 (2006)

8. J. Helene and M. Giroux, Food Hydrocolloids, 18, 665-689 (2011)

9. N. S. Rodionova, I. P. Shchetilina, and N. A. Rodionova Bulletin of the Voronezh State University of Engineering Technologies, 80, 150157 (2018)
10. L. E. Glagoleva, M. I. Korytin, A. A. Rodionov, and N. A. Pastukhova, "Development of a range of probiotic products with immunomodulatory properties proceedings: "Physical and colloid chemistry - the basis of new technologies and modern methods of analysis in chemical and food industries," Voronezh state University of engineering technologies; under the General editorship of Professor T. A. Kuchmenko. Voronezh, 79-82 (2016)

11. N. S. Rodionova, I. P. Shchetilina, T. A. Razinkova, and I. A. Karapuzova, Economics and Entrepreneurship, 7(96), 1153-1160 (2018)

12. L. Zhang [et al.], World J. Microbiol. Biotechnol, 29, 127-135 (2013)

13. M. Candela, Int. J. Food Microbiol, 125, 286-292 (2008)

14. A.F. Bluger, Structure and function of the liver in epidemic hepatitis. SYNTEG (2017) 